\title{
meeting reviews
}

\section{Review of the 18th Conference on Agriculture and Forest Meteorology}

\author{
L. W. Gay* \\ Conference Chair
}

The Eighteenth AMS Conference on Agricultural and Forest Meteorology was held at Purdue University in West Lafayette, Indiana, on 15-18 September 1987 in conjunction with the Eighth AMS Conference on Biometeorology and Aerobiology and the Eleventh International Congress on Biometeorology (sponsored by the International Society of Biometeorology, or ISB). This was the fifth consecutive time that the AMS technical committees have scheduled their biennial conferences together. This was also the second joint conference of Agricultural and Forest Meteorology with ISB.

\section{Organization of the conference}

The Agricultural and Forest Meteorology Conference was organized around five themes: (1) air, canopy, and soil interactions in crop microclimates; (2) evapotranspiration; (3) forest meteorology; (4) remote sensing applications; and (5) effects of climate on productivity. The program was subdivided into 15 sessions, including several held jointly with the accompanying conferences. The joint session with the Eighth AMS Conference on Biometeorology and Aerobiology focused on plant and insect biometeorology. Joint sessions with ISB dealt with microclimate-organism interactions, remote sensing, and impacts of weather on agricultural productivity. An evening poster session provided the opportunity for interaction between speakers and participants on a well-diversified range of topics. Two additional evening discussion sessions provided an informal setting for interchanges on research applications in forest meteorology, and on the current status and future directions in agricultural meteorology. Participants in the three conferences also came together for two luncheons and one banquet.

\footnotetext{
* School of Renewable Natural Resources, University of Arizona, Tuscon, AZ 85721
}

(c) 1989 American Meteorological Society
The luncheon organized by agricultural and forest meteorology conference featured an address by Norman J. Rosenberg on "Future Directions in Agricultural Meteorology" (see accompanying article). The other luncheon was organized by the biometeorology and aerobiology conference, and the banquet by ISB .

\section{Air, canopy, and soil interactions in crop microclimate}

This area remains the focus of fundamental studies in agricultural meteorology.

a. Aerodynamic aspects of a vegetated surface

(Session 1: L. E. Hipps, chair)

Lin and Miller introduced a spatial averaging method for turbulent flows in a plant canopy for both field data analysis and numerical modeling using a second-moment closure. Schuepp et al. discussed the effects of boundary layer dynamics on airborne mapping of regional moisture and $\mathrm{CO}_{2}$ exchange, and reviewed recent advances in the concept of fractal geometry. The degree of intermittency in the boundary layer turbulence structure posed a particular problem for airborne mapping. Meyers addressed the importance of leaf boundary layer resistances in modeling fluxes and profiles within and above a plant canopy. Fluxes and profiles of $\mathrm{HNO}_{3}$ showed greater sensitivity to leaf boundary layer resistance than did $\mathrm{O}_{3}, \mathrm{SO}_{2}$, and heat and water vapor.

Paw $U$ and Meyers presented results of a higherorder turbulence closure model to describe turbulent flows within or above a plant canopy. The model predicted a changing zero plane displacement as a function of stability, and showed that roughness lengths and displacement heights varied throughout the crop season.

Hatfield reviewed experimental results from irrigated and dryland cotton.

In a wind-tunnel experiment, Chen et al. examined 
turbulent resonance in leaf boundary layers and concluded that the most effective eddies associated with leaf property exchange were generally smaller than leaf dimension.

\section{b. Microclimate}

(Session 3: A. Weiss, chair)

The five papers presented in this session displayed the breadth of research in the area of microclimate. Argete and Wilson reported on a series of experiments to determine the modification of wind speed, temperature, and humidity in small square fenced plots of $D / H=8$ and 16 , where $D$ is the fence side length and $H$ is the height. They concluded that in order to gain benefits beyond reduced wind speed, plots must be small in terms of $D / H$. Of the variables measured, the differences between upwind and fenced plot conditions can be related to the differences in the standard deviation of the turbulent vertical velocity.

Boyer and Feldhake presented a preliminary study of air and soil temperatures in an Appalachian watershed with respect to slope aspect and percent of southern sky obscured by topography and dense vegetation. The object of this study was to improve forage yield and quality on steep slopes. Mean air and soil temperatures were highly related to topographically altered daylength periods. The relationship was strongest early and late in the growing season.

In preparation for the First Field Experiment (FIFE) of the International Satellite Land Surface Climatology Project (ISLSCP), Asrar, Harris, and Cooper compared the radiative surface temperatures from in situ and aerial measurements of burned and unburned areas in a tallgrass prairie. From a thorough error analysis, they concluded that unburned areas of tallgrass prairie could be delineated from unburned areas, using emitted thermal radiation detected by airborne sensor systems.

The projection of a unit leaf area in any direction, $G(0)$, is needed in order to evaluate light penetration into a canopy. Baiden and Hipps inverted a radiation transfer equation to recover $G(0)$ from inputs of incident global and diffuse Photosynthetically Active Radiation (PAR), leaf area index and total PAR at the level of interest in the canopy and reported the range of values of this function as distorted by wind speed. Sun and Wu used a model of the planetary boundary layer to predict the diurnal variation of radiation, moisture, and temperature at the ground surface as well as the wind, temperature and humidity in the lower atmosphere under clear or cloudy sky conditions. The model results were in good agreement with the observed temperature, humidity, and wind from the ground surface up to $2 \mathrm{~km}$ during days $33-35$ of the Wangara experiment, as well as with other experimental data.

\section{c. Microclimate organism interactions}

(Session 4: K. Hubbard, chair)

This joint session with the International Congress of Biometeorology dealt with a range of subject matter relating climate to the biological environment. The survival of plants and insects which overwinter in the topsoil layer depends on exposure to extreme cold and depth of snowcover. Hayhoe and Mukerji used observed and simulated data to develop an empirical relation between snowcover and temperature in the upper soil layers. For summer conditions, Sager and Hubbard tested a model for the relationship between temperature and humidity and the spider mite population in a corn canopy. Preliminary results were good, and additional work is underway to improve the model's treatment of soil data, advection, and the incorporation of distant weather station data. In a related paper, Carlson and Gage demonstrated the importance of temperature in predicting corn phenology and insect growth stages, as the relative phasing of crop and insect phenologies affects the potential for yield reductions.

The duration of leaf wetness plays a role in the development of fungal or bacterial plant diseases. Weiss and Norman reported good agreement between leaf wetness measurements and predictions from a mechanistic plant-environment model. Russo et al. generated surface weather data from the 850 $\mathrm{mb}$ output of the National Meteorological Center's nested grid model for input into a local plant disease model. The model used humidity and temperature to predict the likelihood of blight infection and daily severity values. Coakley and McDaniel also developed a model to identify climate variables that were most highly correlated with plant disease, and made successful application to two different foliar pathogens on winter wheat. Avissar and Mahrer introduced a pseudo three-dimensional numerical model for the computation of the latent heat flux from the ground surface. This model accounts for horizontal inhomogeneities, which is lacking in the one-dimensional models, but assumes negligible horizontal fluxes.

\section{Evapotranspiration}

This remains an active research area in agricultural meteorology, although the opinion was voiced during one of the discussion sessions that this topic receives undue attention, given that practical problems in evapotranspiration have been resolved.

a. Evapotranspiration and energy balance

(Session 2: B. D. Tanner, chair)

Diverse topography and random location of trees al- 
ters the wind profile of pastures as compared with cultivated field crops. Feldhake discussed an alternative method for calculating aerodynamic and canopy resistance of pastures as a function of soil moisture, climate parameters, phenological growth stage, canopy height, and time. Fritschen summarized surface energy and radiation balance measurements on different aspects of the Konza Prairie in Kansas, and found largest Bowen ratio values (lowest ET) on the west facing slopes. Since soil temperature information is available for only a few selected soils at widely dispersed locations, Matthias developed a simple, semi-empirical energy balance model for estimating long-term daily mean temperatures at a shallow depth. Results with bare agricultural soils were quite promising. Kunkel evaluated the diurnal dependence of sensible and latent heat fluxes over a lightly vegetated vineyard. His model results agreed well with measured sensible heat flux, but agreement with latent energy was lower because of difficulties in estimating soil evaporation. Mahrer et al. used a numerical threedimensional local-scale model, based on the equations of motion, heat, humidity, and continuity in the atmosphere, as well as the equations of heat and moisture diffusion in the soil, to generate local maps of evapotranspiration. The estimates were compared with observations at field sites in the Gilboa region of Israel. Meyer et al. studied the feasibility of using National Weather Service forecast variables as input for potential evapotranspiration projections, and concluded that daily estimates can be improved by substituting forecast temperature in place of normal temperature.

\section{b. $\mathrm{CO}_{2}$ and water use efficiency}

(Session 8: M. Y. Leclerc, chair)

Malek et al. demonstrated the feasibility of automated, continuous measurements in a remote desert in their micrometeorological investigation on the margin and playa of Utah's west desert. The sensitivity of regional evapotranspiration estimates to error in both radiometrically-derived surface temperature and estimated surface transfer coefficient was defined by Paw $U$ et al. Berard and Thurtell used a whole plant enclosure system to study the effect of high evaporative demand on photosynthesis in corn. The average photosynthetic rates were $6-8 \%$ greater in high humidity (low evaporative demand) than in low humidity. Barr and King examined the influence of $\mathrm{CO}_{2}$ enrichment and vapor pressure difference on maize transpiration in a controlled environment, and concluded that transpiration is less restricted at elevated ambient $\mathrm{CO}_{2}$ concentrations. Clement and Verma evaluated the fluxes of carbon dioxide, water vapor, and sensible heat over a wheat crop, using the eddy correlation technique. McGinn and King com- pared simultaneous measurements of water vapor, heat and carbon dioxide exchange over corn and alfalfa. Corn typically had a larger sensible heat flux and a more variable $\mathrm{CO}_{2}$ flux than did alfalfa. Chen presented a theoretical study of an evapotranspiration model using remotely-sensed plant canopy temperature. Wall and Baker employed chamber systems to grow spring wheat under controlled ambient air temperatures and atmospheric $\mathrm{CO}_{2}$ concentrations with natural radiation, and studied the long-term consequences of different temperatures and elevated $\mathrm{CO}_{2}$ levels.

\section{Forest meteorology}

Many research problems span both agriculture and forestry. However, the scale of forest canopy elements have contributed to a distinct and active research program on turbulence and exchange processes.

\section{a. Canopy turbulence}

(Session 12: D. D. Baldocchi, chair; Session 13: T. P. Meyers, chair)

During similar conferences, the need for additional measurements of turbulence structure inside plant canopies was identified in order to test and provide guidance for the current higher-order closure and Lagrangian models of within-canopy turbulence. Consequently, two sessions at this meeting were devoted to turbulence measurements within and above forest canopies. The majority of papers reported results from recent field campaigns. These include studies of a deciduous forest near Camp Borden, Ontario, an almond orchard near Chico, California, a spruce forerst in Manitoba, and a deciduous forest near Storrs, Connecticut. A common theme describing turbulence structure inside the canopy evolved. Turbulence is characterized as being very intermittent and nonGaussian, resulting in large turbulence intensities and kurtosis values and non-zero skewness values. Spectral computations showed that the foliage elements act to short-circuit the normal eddy cascade of turbulence; slopes of the turbulence spectra at frequencies greater than that at the peak are much steeper than those commonly observed in the surface boundary layer.

Three papers discussed the Camp Borden experiment. LeClerc et al. showed that countergradient diffusion of heat was a daily occurence. Correlations of vertical velocities confirmed that large coherent structures swept all measurement levels in the forest simultaneously. Turbulence from top of canopy produced positive skewness when upward, and negative skewness when downward. Finally, in-canopy spec- 
tra illustrated the short-circuit of cascading eddies in the inertial subrange. Shi et al. reported on the effects of atmospheric stability on turbulence in forest canopy. As stability (denoted as the ratio of canopy height to the Monin Obukhov length scale) went from negative (unstable) to positive (stable), reductions occurred in turbulence intensity, normalized Reynold's stress, wind speed, and drag coefficient. These results contradict Shaw's theoretical predictions for a short agricultural crop, as presented at the 13th Agricultural and Forest Meteorology Conference (1976), as buoyancy effects are much more significant in tall plant canopies. In a second paper, Shi et al. presented cross correlations of turbulence at various heights within and above the canopy. Temperature signals measured inside the canopy were found to lag behind those measured above the canopy by several seconds. On the other hand, the cross correlations of vertical velocity $(w)$ at various heights show no apparent lag with measurements made above the canopy. The cross correlation between static pressure and vertical velocity show a consistent pattern of positive correlation when a negative lag is applied to $(w)$ and a negative correlation when a positive lag is applied.

Three papers discussed the Chico almond orchard experiment. Cionco described the experiment and field site and showed how the wind speed profiles developed as wind flowed from an upward clear field, to the edge of the canopy, and into the orchard. Baldocchi discussed three-dimensional turbulence measurements made inside the orchard. He showed that strong shear occurs in the upper canopy and the tangential momentum stress in the crown is due to very intermittent, but intense sweep events. The uniformity of the orchard canopy leads to regions of preferred flow and areas with strong secondary circulations in the subcanopy trunk space. The foliage and woody biomass of the orchard affects the shape of the turbulence spectra, as discussed above. Amiro presented turbulence statistics for the horizontal and vertical velocity components measured in a Manitoba spruce forest. Profiles of turbulence intensity mimic that of the foliage, with maximum turbulence occurring at the height of crown closure. Spectral measurements show a strong drop-off in the spectral slope at frequencies exceeding the peak. Thistle et al. presented turbulence velocity data collected 2.5 canopy heights downwind of a deciduous forest edge in Connecticut for both fully leafed and leafless conditions. The power spectra of the mean wind velocity in the trunk space showed difference between the foliated and defoliated cases. The turbulent spectra measured in this canopy show a well-defined inertial subrange.

Bergen presented data on the variances of $u$ and $v$ normalized by friction velocity measured over a for- est. He found no influence of the canopy on these variables and found results similar to those published from the O'Neill, Nebraska, study. Leclerc et al. reported in a second paper on the results of a tracer release experiment within an alfalfa canopy. They validated a new diffusion model which bypasses the concept of a mean upward velocity. It accounts for diffusion in presence of a gradient in vertical velocity (as in vegetation) by using a probability of reflection at each step of the trajectory. Childs et al. demonstrated use of autocorrelation analysis to obtain information on sunflect return intervals with a canopy.

\section{b. Mass and energy exchange}

(Session 14: K. M. King, chair)

Five papers in this forest meteorology session dealt with exchanges of mass and energy between forested land areas and the atmosphere. In three of these studies fluxes were measured by eddy correlation. den Hartog et al. reported on eddy correlation measurements of the turbulent fluxes of ozone, sulphur dioxide, carbon dioxide, sensible heat, and latent heat over a deciduous forest near Borden, Ontario. The time trace of the ozone and $\mathrm{CO}_{2}$ fluxes were very similar. Deposition velocities calculated each halfhour were quite variable; averaging times of 2-3 hours were suggested. Spectral analysis showed dominant scale size to be large, ranging from 100 to $300 \mathrm{~m}$ at a mean horizontal wind speed of $3 \mathrm{~m} \mathrm{~s}^{-1}$, confirming that frequency response of instrumentation was less demanding than over shorter and smoother surfaces. Edwards and Northrup used a diode laser spectrometer at the Borden deciduous forest site to measure the dry deposition fluxes of $\mathrm{SO}_{2}$ and $\mathrm{NO}_{2}$. A fastresponse, tunable diode laser absorption spectrometer was located on a tower $12 \mathrm{~m}$ above the forest canopy and used in an eddy correlation technique with sonic anemometry to measure the fluxes. Measurements over the autumn leaf period showed the method was suitable for measuring the fluxes from full leaf to near-zero foliage. Amiro and Thorne used an energy balance approach, with sensible heat being measured with a vertical propeller anemometer and thermocouple, to measure the evapotranspiration and estimate the water balance of boreal forest catchment areas over a summer season. The upland areas had a sparse jack pine canopy and bare-rock regions whereas the lowland areas were covered with trembling aspen and willows. Precipitation, soil moisture, and runoff were also measured. The eddy correlation/energy balance ET estimates agreed well with results from the hydrologic water balance.

Bernier employed an interesting experimental approach to find out how much snow evaporation protection is provided by small trees after logging. In the fall of 1986, 400 lodgepole pines were tied to iron 
stakes driven into the ground in an open pasture. The trees were placed on an $2 \times 2 \mathrm{~m}$ grid to form an artificial stand in the form of a semi-circle, facing into the prevailing westerly wind in the foothills of the Rockies in Alberta. Although snow evaporation was predicted well in the open by an aerodynamic technique, the same equation overestimated evaporation in the stand by $50 \%$ or more, where snow evaporation was only about $30 \%$ of that in the open.

Mueller described a field study on chemical deposition to a mature red spruce forest on Whitetop Mountain in southwestern Virginia. The amounts of ozone, sulphate, and nitrate, by wet deposition, dry deposition, and cloud water deposition mechanisms are being determined on a seasonal basis.

Finally, Heddinghaus et al. discussed usefulness of the $\mathbf{Z}$ index of the Palmer Drought Severity Index as an indicator of potential forest fire ignition. The index was found to be a good indicator of the occurrence of forest fires during 1986 in the southeastern United States, where a pilot test of this system has been operating continuously since January 1983.

\section{c. Remote sensing application in agriculture}

(Sessions 5 and 7; B. Choudhury, chair)

Remote sensing techniques provide tools for observing spatial variations in crop conditions. Pinter et al. reported on field experiments of alfalfa biomass using handheld spectral radiometers. Analyses revealed vegetation index values computed as ratios of nearinfrared and red reflectance factors were less sensitive to cloud cover than single band reflectances or linear band combinations. They also reported that surface temperatures in an incomplete canopy cover can be estimated as a composite of the soil and vegetation temperatures. Kustas et al. used micrometeorological and thermal infrared data to demonstrate an increased resistance to heat transfer under partial canopy conditions, leading to potentially large errors when latent heat flux is estimated from surface resistance models. Choudhury used $18 \mathrm{GHz}$ brightness temperatures from satellites to calculate an antecedent precipitation index as an estimator of surface wetness. Yang and Timchalk reported good results in the relationship between satellite microwave data and precipitation detection over land. Desjardins et al. used airborne instrumentation to measure $\mathrm{CO}_{2}$ and $\mathrm{H}_{2} \mathrm{O}$ fluxes at an altitude of $50 \mathrm{~m}$ over cultivated and noncultivated areas. Comparisons with Landsat-D multispectral scanner data confirm the promise of this approach for assessing crop conditions on a regional scale.

Gallo and Flesch used NOAA-AVHRR (Advanced Very High Resolution Radiometer) visible and NIR data to identify the silking stage of development in the U.S. corn belt. Results compared well with tem- perature-driven models. Kogan reviewed a modification of Normalized Difference Vegetation Index data for areal monitoring of vegetation, based on a concept of ecological potential of an area. Heinemann and Russo demonstrated the potential for identifying frost sensitive locations from satellite observations by generating high resolution surface temperatures from terrain-enhanced thermal images. Attenuation of light in plant canopies is complicated by geometrical problems of plant architecture and natual variation of leaves. Myneni et al. discussed various forms of the canopy radiative transport equations, and in a following paper presented some numerical solutions of the canopy transport equation. Esser and Lieth evaluated the use of Landsat data to detect and quantify areal distribution of land use changes. Monthly estimates of the absorbed photosynthetically active radiation were derived by Dye from AVHRR's spectral vegetation index data. The efficiency of annual vegetation biomass production based on these estimates compared favorably with reported field experiments. Scurlock et al. found that while the red to near-infrared reflectance ratio was a good indicator of canopy parameters for an actively growing canopy, the presence of dead material tended to produce underestimated periods of slow growth. Wickham and Kautz presented preliminary results of the capability of Landsat's Thematic Mapper data to detect Florida's numerous natural plant types. Box discussed the improvement in global ecological monitoring obtainable by combining satellite data with bioclimatic models.

\section{Effects of climate on agricultural productivity}

\section{a. Impacts of climate change and variable seasonal weather on agricultural production}

(Session 10: W. L. Decker, chair)

The first of three sessions devoted to climate change and agricultural weather impacts focused attention on possible causes of climate variability. MacCracken noted that carbon dioxide and other trace gas concentrations have increased rapidly over the past several decades. The projections of increased global warming resulting from higher concentrations of greenhouse gases have serious implications for agriculture. These include a lengthening of the frostfree season with drier summer conditions in midlatitudes, reduced water input to reservoirs from the rising snowline at higher latitudes, and continued increases in sea level affecting coastal lowlands. Decker et al. emphasized that agriculture responds to changes in climate; therefore management, production, and the support infrastructure also respond dynamically 
to climate variability. Walker reviewed modeling approaches (regression and simulation) for crop production estimation over the Canadian prairies. A drought index model incorporating both approaches was found to adequately explain interannual yield variation and to offer potential for analysis of climate change scenarios. Thompson presented results of regression models showing a cyclical pattern of corn yields in Illinois and lowa from 18 to 20 years in length. A 20-year drought cycle was evident in the data. Handler successfully correlated United States corn yields with volcanic eruptions, El Niño events, strength of the Indian Monsoon, and frequency of tropical storms in the North Atlantic Ocean.

\section{b. Climate and agricultural productivity \\ (Session 11: G. K. Walker, chair; Session 15: \\ S. E. Hollinger, chair)}

The first of the two sessions contained a diverse group of papers, generally addressing problems related to crop production estimation over large areas. The session began with a particularly relevant paper on yield forecasting for the Sahelian region. Sakamoto and Steyaert described two independent forecasting approaches, based on either weather data or NOAAAVHRR satellite data. These methods were practical, with near real-time applicability, and the results gave some hope that crop failures in the Sahelian region can now be more reliably detected than in the past. The lack of an adequate network of reporting weather stations in areas such as the Sahel poses a major problem for weather-based agricultural monitoring systems. This has led Callis and LeComte to use satellitebased, precipitation estimates from Meteosat. The cloud-indexing technique that they describe is labor intensive and subjective, yet once calibrated it offers possibilities for improving the spatial resolution of precipitation estimates. A fully automated technique would clearly be desirable, but the authors do not consider this attainable, concluding that human input is essential for best results. A rainfall estimation problem of a rather different kind was presented by Jager, who tackled risk assessment for maize production in South Africa where farmers must contend with considerable interannual precipitation variability. Maize yield and precipitation time series were too short to provide stable risk estimates, so Jager estimated precipitation by using a Markov chain approach that generated sequences of rain/no-rain days. With a crop growth simulation model, Jager then obtained risk estimates from a 100-year series of modeled yields. Agreement with independent risk assessments was encouraging. Hollinger and Mjelde examined the role of temperature in yield estimation in the United States corn belt by defining and calculating termperature indices for successive growth stages, and combining these to obtain seasonal values. Their results suggest that careful consideration of temperature can lead to improved maize yield forecasts. In some areas of the world, notably in the USSR, wheat can suffer substantial yield losses from "sukhovei" events that are characterized by hot, dry winds. Brusberg, Puterbaugh, and Huffman used Penman-style, potential ET estimates to tighten up identification of these events, leading to a practical improvement over earlier schemes. China produces more wheat than any other country, and Henan is the most important province in China for wheat-a kind of Chinese Kansas. Yonggin et al. gave new and interesting information on regional variations in the weather factors that influence yield in Henan Province. Agricultural decisionmaking at all levels requires volumes of data. Russo discussed how to organize, scale, and present databases for decision-making. Complete databases are clearly a long way off, but Russo presented a conceptual layout useful to those in the unenviable position of having to layer many different data types collected at a variety of temporal and spatial scales.

In continuation of this topic in session 15, Andresen et al. estimated county corn yields in Indiana using a modified energy crop growth (ECG) index and its interactions with applied nitrogen. The modified ECG index was obtained by combining daily estimates of a corn growth function with the ratio of actual to potential ET and an exponentially weighted estimate of solar radiation intercepted by corn leaf area each day. Best yield predictions were obtained by summing the modified ECG index over a period from 16 days prior to and including silking, to 20 days after silking. Sonka et al. evaluated the value of climate predictions to production agriculture as functions of the accuracy and lead time of the climate forecasts. A detailed corn simulation model and a decision process model were used to obtain yield estimates for 14 years with different management practices to determine how management decisions during different times of the growing season affect the economic return under different weather scenarios. The most valuable forecasts were those for the early summer period (June 11 to July 15) because of their effect on nitrogen management decisions. Finally, interdisciplinary research is needed to address the issue of climate change and its economic impacts on agriculture. Sonka and Lamb proposed a method of linking physical soil and crop models with economic models of different levels of aggregation to anyalyze the effects of changing climate.

\section{Miscellaneous interactive sessions}

The conference schedule included an evening poster 
session and two evening discussion sessions to facilitate communication among participants.

\section{a. Poster session (R. F. Dale, chair)}

The poster session provided an excellent opportunity for more informal interactions between participants. Bingham et al. displayed a microclimate station for unattended operation that incorporates measurements necessary to estimate actual water loss using the Bowen ratio method. Fuentes and King studied the relationship between stomatal conductance and photosynthesis as well as the association between high photosynthetic rates and high corn yields in soil-grown plants and hydroponically grown plants. Both treatments experienced similar stomatal conductance trends throughout the season and leaf photosynthetic rates were not correlated with dry matter yield. Flint and Childs used model coefficients dependent upon soil water content to adapt and calibrate the Priestley-Taylor equation when actual ET is less than potential ET during soil-water limited conditions. Bourgue displayed a model for above-canopy turbulence measurements in the convective boundary layer and discussed its potential role in assessing forest spray drift. Two posters described programs that analyze and disseminate agricultural weather information to the user community on a near-real-time basis. Brown reviewed the development of Arizona's AZMET information system, and Seeley and Graham reported on Minnesota's survey of end-users on the importance and utilization of agricultural weather information. The most frequently utilized information in Minnesota included precipitation probability, freeze/ frost warnings, soil moisture, and temperature reports for the next 48-hour forecast period and the 3-5 and 6-10 day outlook. Finally, Quate used sunspot cycles to predict monthly precipitation over agricultural areas.

\section{b. Discussion Session: Future directions in agricultural meteorology}

(A. Weiss, chair and rapporteur)

The past several conferences have included informal discussion sessions on topics of interest to agricultural and forest meteorology. This summary of the Purdue discussion of agricultural meteorology attempts to capture some of the ideas expressed, and thus prove useful as a point of reference at future conferences.

The discussion session began with the view that science is entering a new era and will develop new patterns of operation. The discussion quickly divided into the concerns of practitioners vs researchers. While practitioners and researchers have different interests, they share a common knowledge base and a common future. Success of the practitioner justifies increased research funding, while successful research will provide the practitioner with new tools. Research efforts to bridge gaps between the two groups could be of practical importance.

Communication with other disciplines and the public is also a problem. We should issue press releases about our meetings, invite colleagues from other disciplines to our meetings, and, conversely, present papers at meetings of other professional societies. However, we may be part of the communication problem. For example, even though many of the practical problems of ET processes have been resolved, someone from a different discipline might gain a perception of an overwhelming concern with ET at the expense of other biological and physical problems. An important task for our group would be documentation of research areas and specific problems suitable for interdisciplinary projects with other physical and biological scientists. This documentation would be used to inform others of our capabilities.

Practitioners should also become involved with the different farm media to educate the public about the different types of information that we can provide. Our responsibility is to demonstrate that this information has value: one way to evaluate "value" is to determine if end users would pay for the information. Extension workers and the news media also have a responsibility to accurately communicate this information to the end user.

Researchers expressed frustration that some granting agencies appear to be biased against agricultural disciplines. There was the perception that ecologists working with natural ecosystems are often given more credibility than agricultural scientists working in manmade ecosystems. Agricultural meteorology is a branch of applied physics; in fact, some of our colleagues prefer to use the term "environmental biophysics" to describe their profession.

From the perspective of this rapporteur, future directions in agricultural meteorology are to

1. increase the value of the information that we provide by studying high risk/high profit fruit and vegetable crops along with the old standbys of wheat, corn, and soybeans;

2. work with plant pathologists in the area of genetically engineered ice nucleating bacteria; we have expertise in field measurements as well as the ability to predict leaf temperatures from energy balance techniques;

3 . determine if we are collecting the right meteorological data to aid in decision making (i.e., days with hail are tabulated, but do we measure intensity, duration, and damage?);

4. develop crop models that take into account quality as well as quantity, since premium prices are paid for the former; 
5. determine if climate databases are adequate in order to assist in the selection of new crops;

6. evaluate data and information needed for aquaculture, as American dietary interest in fish increases; and

7. evaluate the status and potential yield of foreign crops so our policy makers can respond to this competition.

\section{Concluding comments}

The 18th Agricultural and Forest Meteorology Conference was the largest and most diverse of this long series of biennial meetings. The association of this conference with ISB increased the international participation. Appropriately, the meeting was held in the fine facilities of Purdue University, which has contributed substantially over the years to research, application, and practice in the field of agricultural meteorology.

The proceedings of this conference were also the largest to date, containing 97 of the 102 accepted papers. The proceedings consists of unedited, camera-ready manuscripts, but most of the papers appear to be substantial contributions that provide a valuable point of reference for current research. Research areas fluctuate in popularity, and it is interesting to note that no papers were volunteered in the area of operational weather forecasting for agriculture. This contrasts sharply with the high level of activity evident in forest turbulence studies and in remote sensing applications. Further, the research presented at this and previous conferences has been oriented toward applications and field experimentation. Perhaps because the team approach is common in experimental research, 72 percent of the accepted papers were submitted by multiple authors. Presentation of experimental results also tends to fit nicely into a program format of 15- to 20-minute papers, which seems to have become the standard in recent conferences of this series. The moderate size of these conferences may also influence the format, as there are approximately 100 "short paper" slots available in a $3 \frac{1}{2} 2$-day period. Poster sessions used in scientific meetings elsewhere have not been well accepted in agricultural and forest meteorology conferences. However, scheduled but informal discussion sessions have proven to be both popular and surprisingly efficient in transferring information.

In retrospect, the 18th Agricultural and Forest Meteorology Conference was quite successful. It has clearly demonstrated that this area of meteorological research is both active, dynamic, and possessing the strength necessary for continued contributions.

\section{RECENT WMO PUBLICATIONS ...}

\author{
The World Weather Watch-25th Anniversary: \\ 1963-1988
}

(WMO 709)

1988 marked the 25th anniversary of the World Weather Watch (WWW) and this book provides a short description of the organization from its earliest development to its growth into the next century. The text effectively conveys the meteorological service's role in this time of explosive technological advances. B\&W and color photographs. ISBN: 92-63-10709-2 \$7.00

\section{Guide on the Global Observing System (WMO 488)}

This revised and extended update of the Guide deals with the organization and implementation of the Global Observing System, one of the three essential elements of the World Weather Watch, the basic Program of WMO. It provides users with general information on observational practices and procedures supplementing those already contained in the Manual on the Global Observing System. Binder format designed for later supplements.

ISBN: 92-63-10488-3 \$42.00

\section{WWW Global Observing System-Satellite Subsystem: Information on Meteorological and Other Environmental Satellites}

(WMO 411)

This completely revised version of publication \#411 contains information on meteorological and environmental satellite programs of 20 countries, and includes the latest satellite techniques, satellite systems and data. Encourages free exchange of ideas in the global meteorological satellite network.

2nd e ISBN: 92-63-12411-6 \$37.00

Also available this month ...

The World Weather Watch 14th Status Report on Implementation

(WMO 714) \$24.00

The Regional Association II (Asia) Abridged Final Report of the 9th Session (Beijing, 5-16 September 1988)

(WMO 711) $\$ 33.00$

Send check or money order in US dollars to:

American Meteorological Society
45 Beacon Street
Boston, MA 02108
(617) 227-2425

Please include \$4 shipping and handling per item

is Residents of countries other than the US and Canada should direct orders to: The Secretary-General, World Meteorological Organization, PO Box 5, CH1211 Geneva 20, Switzerland. 


\title{
Speculations on the Future of Agricultural and Forest Meteorology*
}

\author{
Norman J. Rosenberg ${ }^{\dagger}$
}

There are three things I've always been wary of: (1) after dinner (or after lunch) speakers, (2) prophets, and (3) people who read their papers to a captive audience.

I have agreed to be your luncheon speaker and to prophesize (more truly, to speculate) about the future only because - as Ray Motha who invited me here knows-flattery will get you everywhere!

My colleagues from Nebraska will testify to my aversion to the institution of the after dinner speech, especially if the subject is a serious one. I have made occasional exceptions to this rule, however. One special event I recall was when Gilbert White presented a talk entitled "The Future of the Great Plains Revisited" in a 1985 symposium of the Center for Great Plains studies at the University of Nebraska in Lincoln. That was living history! As a young man, Professor White was a member of the staff that prepared that remarkable report for President Franklin D. Roosevelt.

As to prophets-I know of no recent ones whose batting averages exceed 0.500 by very much. In the prophecy business, that's not too good. Now that I find myself at Resources for the Future, a nest of economists and social scientists, I see even less cause for confidence in the power of prophecy.

Nonetheless, I am supposed to speculate on the future of agricultural and forest meteorology. Before we look to the future, however, let's look a bit to the past. We begin with Aristotle, who is reputed to have said "Wind is more influential than sun in evaporating water," (or words to that effect). Why a Greek living in a maritime environment would reach this conclusion is unclear to me. A Sioux Indian, on the other hand, I would understand. Nevertheless, 25 years of evapotranspiration research on the Great Plains has convinced me that Aristotle was about right.

We should also look to the record assembled by Chinese agriculturalists who, over 40 centuries, laid down rules (even in poetry) for the annual cycle of crop cultivation based on careful observation of

\footnotetext{
* Text of a talk given at the 18th National Conference on Agricultural and Forest Meteorology

'Senior Fellow, Director, Climate Resources Program, Resources for the Future, 1616 P Street NW, Washington, DC 20036

๑1989 American Meteorological Society
}

phenological phenomena. Let us "fade," as the moviemakers say, to the era of Geiger, Sauberer, and other central and eastern Europeans and their systematic instrumental observations of microclimate and its effects on plant growth and their insightful interpretations of cause, effect, and interaction. Practical agrometeorologists were at work on this continent, too. They called themselves agronomists or maybe soil scientists-Briggs, Shantz, King, and Keisselbach, among others. Their papers and texts still provide a wealth of useful insights to the beginner and the long-time practitioner. Naegeli, a Swiss contemporary of Geiger, did studies of windbreak microclimate that were very influential in development of my own research program in Nebraska.

Another person, Eiichi Inoue, did seminal work that, to my mind, initiated the modern era in agricultural meteorology. Inoue, barred from his work in aeronautical engineering after World War II by the terms of the United States occupation of Japan, turned his inventive mind to the study of the aerodynamics of plant movements in wind and then to estimating photosynthesis and evapotranspiration on the basis of aerodynamic principles.

Thornthwaite and Holtzman throughout the 1940s, and Penman beginning in the late 1940s provided insight as to how evaporation and transpiration could be estimated from meteorological measurements and predicted with the aid of climatology. Priestly and Tanner, a decade later, furthered our understanding of potential evaporation and evapotranspiration, and many more contemporary and still-active contributors have elaborated on these subjects, principles, and measurements. We owe a great debt to these people and to such leaders as Shaw, Newman, Dale, Decker, Van Bavel, Lemon, Waggoner, Monteith, Reifschneider, and a good many others who contributed to our understanding of why crops and forests grow where they do; how their growth is affected by weather, climate, and microclimate; how alteration of the earth's surfaces change the balance of radiation and energy and hence the microclimate, the climate, and (probably) the weather; and how the scientific principles identified can be applied to better management of our fields and forests.

Should we be really concerned about better management? Don't we have enough food and fiber? Perhaps we do now, although a good share of the 
world's people are still ill-fed. But excess production is surely a transitory situation as the population of this planet continues to explode. Agricultural and forest meteorologists have a good deal of work-in fact, an urgent agenda of work waiting for them.

Today, "ag" and forest meteorologists

1. interpret weather and satellite information in order to monitor prospects of world food supply for governments and for the private sector;

2. provide surface observations for the calibration of remote sensing systems on satellites and aircraft;

3. develop sensors for field measurement of evapotranspiration, photosynthesis, respiration, and other phenomena that control these processes;

4. develop models for forecasting plant development and yield using daily and monthly climatic data;

5. develop mathematical simulations of photosynthesis, plant growth, evapotraspiration, and respiration processes in which hourly or more frequent time steps of microclimatic inputs are used;

6. conduct energy balance studies of natural ecosystems and of the surface changes made by mankind that can affect climate;

7. develop crop management systems such as Comax-Gossym (Reddy et al. 1987) in which weather and climate data are used to guide crop management step by step throughout entire seasons;

8. conduct open-air chamber studies and soon genuinely open-air studies of carbon dioxide enrichment effects on photosynthesis, plant growth and evapotranspiration; and

9. operate networks of automatic weather data systems that provide near-real-time information on the agriculturally important weather parameters-information for media, extension specialists, researchers, consultants, farmers, and ranchers (Hubbard et al. 1983).

This list of important ongoing activities in agricultural and forest meteorology is incomplete, at best, but even this short list encompasses a number of activities barely thought about 25 years ago when I stumbled into the field as one more thirsty refugee from the desert of soil physics.

Now what about the future?

In one sense the future is already here. The following currently important activities will surely continue.

1. The work underway in calibrating satellite systems is essential and must continue. The Hapex-Mobilhy study in the Toulouse region of
France (Andre et al. 1986) and the FIFE (First ISCLP Field Experiment) study conducted this summer at Konza prairie in Kansas (Schmugge and Sellers 1986) have been very successful. No doubt not all the answers have been found and more such studies will be needed over other types of terrain and in different ecosystems.

2. The principles of energy balance are well established; yet there is still much that is unknown about how land-use changes, such as large-scale irrigation, deforestation, reafforestation, and so on impact upon microclimate, mesoclimate, and meso-weather of the altered regions and the regions downwind.

3 . Instrumentation for eddy correlation measurements of carbon dioxide and water vapor flux rates has improved. Now it is time to apply this technique to measurement of the fluxes of such trace gases as methane and nitrous oxides and perhaps others.

4. There is already considerable emphasis on development and use of simulation models in agrometeorological research and for management of agricultural systems. I suspect the same is true for forests. Simulation modeling will surely continue to gain in importance as a research and management tool and will be applied to more and more complex problems. The archiving of models and attempts to make their parts accessible and even interchangeable - an effort currently beginning under the auspices of the Agricultural Research Service-is likely to facilitate the further development and use of such models (Heller and Rawlins 1986). Here I cannot resist interjecting my usual caution, however. Models are no better than the data used in their development. There is a trend which I find troubling in many fields of sciencephysical and social alike-where data are used as grist in the model mills without sufficient understanding as to how the data were arrived at and without sufficient assurances as to their quality. Simulation cannot make silk purses from measurements that are sow's ears.

5. It seems inevitable that greater use will be made of automated weather data networks for all of the purposes I described before as well as for input to operational management systems.

6. "Ag" and forest meteorologists will play a greater role in site-specific studies of carbon balances. Still a great deal is unknown about which of the earth's ecosystems are net sources and which are net sinks for carbon dioxide. The tools of agrometeorology are clearly applicable to this question. 
7. There is an important role for "ag" and forest meteorologists in explaining the issues of climate change to the public. I raise this matter because I feel our profession fits us, perhaps better than most scientists, to understand the physical and biological aspects of the climate change issue and to see it in perspective. The problems of climate change are certainly complex and the implications astounding-sea level rise; dislocation of established agricultures due to high temperature and dessication, or perhaps to excessive rainfall; the opening of new frontiers to agriculture in the high latitudes; losses of forest lands and changing species composition; recapture of fossil fuel $\mathrm{CO}_{2}$ by forest regrowth; political turbulence, etc., etc., due to the uneven nature of the possible impacts. A journalist's dream! But what is dream? What is reality? What are the options for abatement, adjustment, and adaptation to climate change? There is much to be done here and I urge you all to study the issues and to be prepared to inform your students, colleagues, and the general public on these questions.

8. Finally a few comments about the IGBP-the International Geosphere-Biosphere Program. I was privileged to serve on the NAS/NRC U.S. Committee for an International Geosphere Biosphere Program which put forward a plan for a program of research to systematically explore, on a global scale, the linkage between climate, soils, the hydrologic cycle, and ecosystem function. This program has been adopted by ICSU (the International Council of Scientific Unions) and plans for a global program are now being developed. My background led me to propose one particular facet that has been adopted as integral to the program-namely the biosphere observatory. This is a scheme to develop a network of sophisticated research stations for detailed ground level, boundary layer, and ground-truth observations of the processes that determine primary productivity.

I commend this idea to you. The report entitled "Global Change in the Geosphere-Biosphere: Initial Priorities for an IGBP" (NAS/NRC 1986) provides more detail. Our profession has a great deal to offer to IGBP, not only in designing and operating biosphere observatories, but in many other ways, e.g. improved parameterization of surface processes for global climatic models, support for ecological and hydrological research, data management, and other essential needs of the program.

In a recent editorial in Climatic Change, Stephen Schneider (1987) points out that IGBP risks failure if it does not develop the interdisciplinary interactions that will be required to tackle the ultracomplex set of problems it has undertaken to address. He extends that idea to encompass not only the biological and physical sciences but the social sciences as well, since the global changes that seem to concern us most at this time are changes that humankind has set under way and that will surely impact upon humankind. Who better than the ag- or forest meteorologist, by definition an interdisciplinarian, to take an important role in these endeavors that will occupy science for many years to come.

So much for prophecy! I hope that these ideas are of interest and will prove useful to our community of scholars.

\section{References}

Andre, J. C., J. P. Goutorbe, and A. Perrier. 1986. Hapex-Mobilhy: A Hydrologic Atmospheric Experiment for the Study of Water Budget and Evaporation Flux at the Climatic Scale. Bull. of the Amer. Meteor. Soc. 67:138-144.

Heller, S. R., and S. L. Rawlins. 1986. Agriculture Systems Research: A New Initiative. Human Systems Management. 6:289-296.

Hubbard, K. G., N. J. Rosenberg, and D. C. Neilsen. 1983. An Automated Weather Data Network in Support of Agricultural Operations. Journal of Water Resource Planning and Management. 109:213-222.

National Academy of Sciences/National Research Council. 1986. Global Change in the Geosphere-Biosphere: Initial Priorities for an IGBP. Washington, DC: National Academy Press.

Reddy, V. R., D. N. Baker, F. D. Whisler, and R. E. Fye. 1987. Application of Gossym to Yield Decline in Cotton. I. Systems Analysis of Effects of Herbicides on Growth, Development, and Yield. Agronomy Journal 79:42-47.

Schneider, S. H. 1987. An International Program on "Global Change": Can It Endure? An Editorial. Climate Change 10: 211-218.

Sellers, P. J., F. G. Hall, G. Asrar, D. E. Strebel, and R. E. Murphy, 1988. The First ISLSCP Field Experiment (FIFE) Bull. Amer. Meteor. Soc. 69:22-27. 

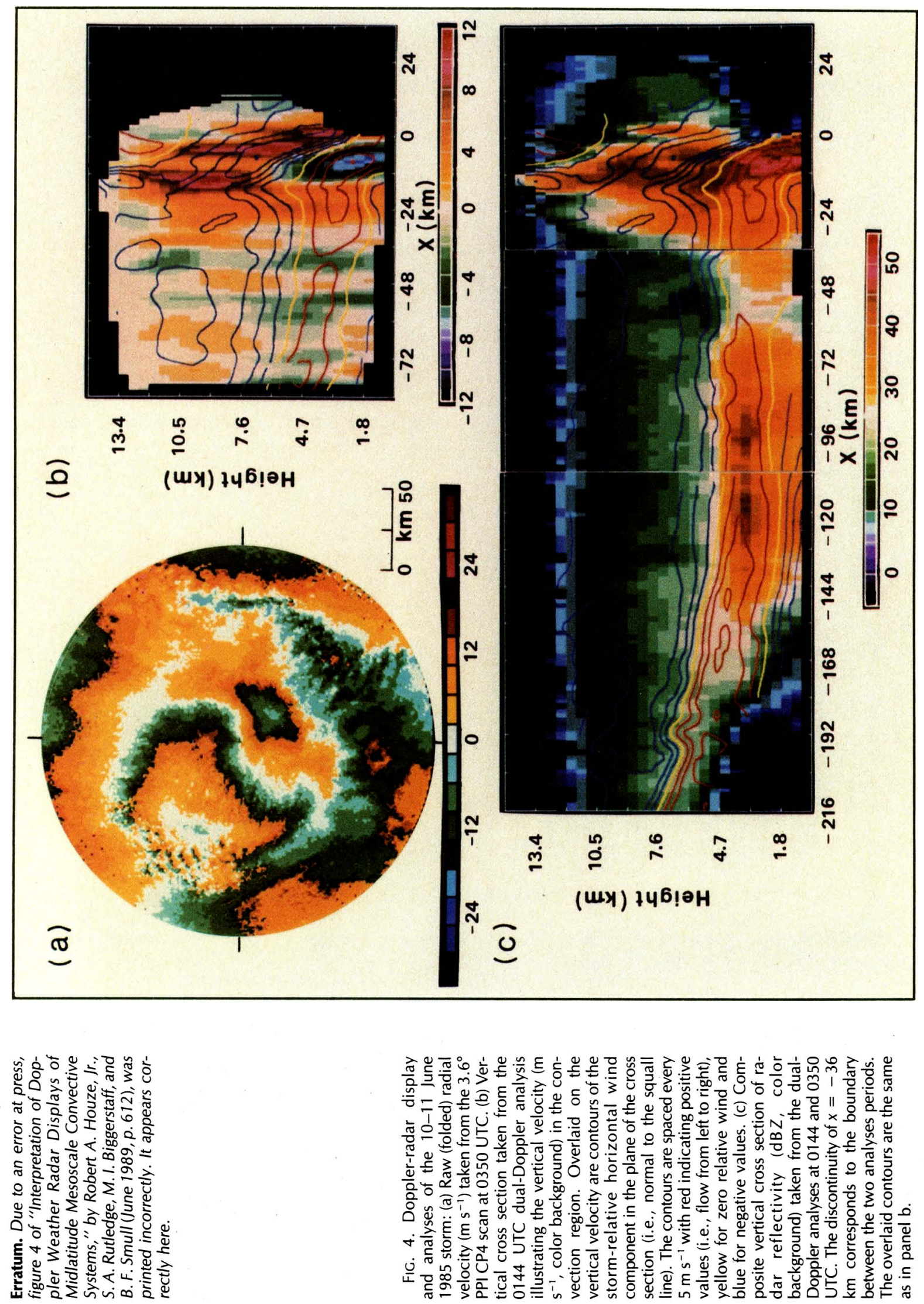

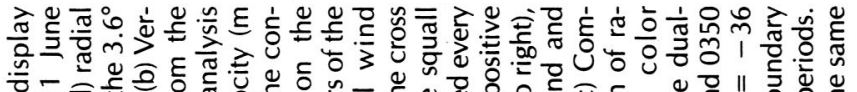

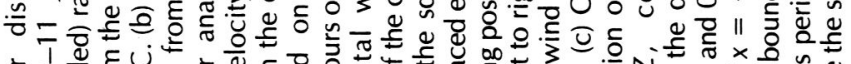

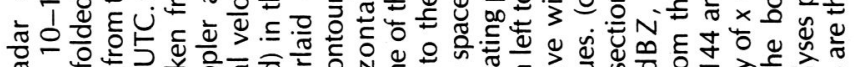

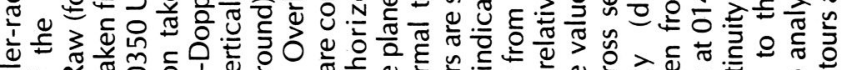

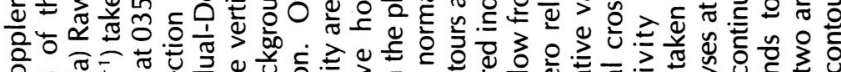

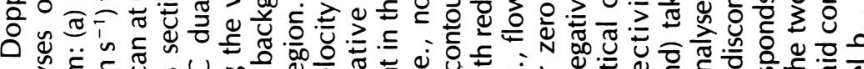

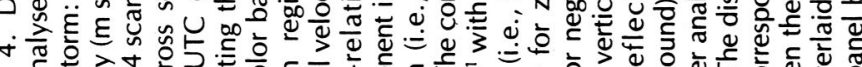

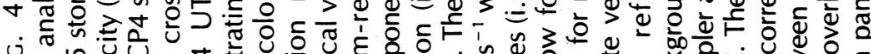

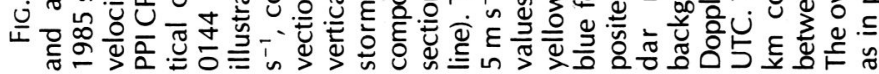

